\title{
Avaliação de Características Habitacionais de Domicílios Rurais em Recortes Territoriais Sergipanos ${ }^{1}$
}

\author{
Andreia Vieira Santos ${ }^{2}$ e Marcos Aurélio Santos da Silva ${ }^{3}$
}

Resumo: A adoção crescente de abordagens territoriais no processo de elaboração de políticas públicas no Brasil tem estimulado uma série de estudos sobre o tema. A heterogeneidade espacial local e a complexidade inerente dos sistemas sociais vinculados ao território sugerem o uso de métodos quantitativos multivariados como ferramentas de auxílio ao planejamento dessas políticas públicas. Este trabalho avaliou características habitacionais de domicílios rurais sergipanos a partir de dados agregados por setor censitário rural de forma a subsidiar os formuladores de políticas públicas em suas decisões sobre a distribuição espacial de recursos direcionados à habitação. Foram analisados diferentes recortes territoriais: municípios, Territórios de Planejamento do Estado e Territórios da Cidadania, utilizando dados do Censo Demográfico 2010. O estudo foi conduzido através da análise fatorial e análise de agrupamentos. Foram identificados três agrupamentos de setores rurais representativos do conjunto de dados estudados. Esses grupos estão presentes nos três recortes territoriais e diferenciaram-se, principalmente, com relação às características de domicílios associadas ao cômodo banheiro e ao destino do lixo.

Palavras-chaves: Análise multivariada; Desenvolvimento rural; Gestão territorial.

Abstract: The increasing use of the territorial approach in the process of public policy design in Brazil has stimulated a series of studies about this theme. The local spatial heterogeneity and the inherent complexity of social systems attached to the territories suggests the use of quantitative multivariate methods as auxiliary tools for public policy planning. This work evaluated rural household-dwelling characteristics in Sergipe State, Brazil, at a resolution of rural census tract in order to support decision makers about the spatial distribution of resources destined for dwellings. It has been analyzed three regional partitions: municipalities, Territories of Citizenship and Territories of State's Planning,

1. Data de submissão: 18 de dezembro de 2014. Data de aceite: 15 de janeiro de 2016.

2. Empresa Brasileira de Pesquisa Agropecuária. Aracaju, Sergipe, Brasil. E-mail: andreia.santos@embrapa.br

3. Empresa Brasileira de Pesquisa Agropecuária. Aracaju, Sergipe, Brasil. E-mail: marcos.santos-silva@embrapa.br 
using demographic census data from 2010. The study has been conducted by using factorial analysis and clustering techniques. Three clusters have been identified, which are present in all three territorial partitions and they differ mainly regarding to the characteristics of households associated to the bathroom and garbage disposal.

Key-words: Multivariate analysis; Rural development; Territorial management.

\section{Introdução}

Nos últimos anos, as políticas de desenvolvimento com enfoque territorial têm se destacado no Brasil (GUIMARÃES, 2011; BOUERI e COSTA, 2013). Apesar do seu significado polissêmico, o território, ou a abordagem territorial, já foi incorporado aos processos de planejamento e execução de políticas públicas voltadas, principalmente, para a diminuição das desigualdades socioespaciais nacionais e estaduais (SABOURIN e TEIXEIRA, 2002; MIRANDA e TIBÚRCIO, 2012). Os planos, programas e ações governamentais territoriais se sobrepõem, se complementam e às vezes se contradizem quanto ao modelo e à forma de desenvolvimento sustentável que se deseja para uma determinada região. De fato, cada território, seja ele um município, uma microrregião, uma bacia hidrográfica, apresentará especificidades locais que devem ser consideradas no momento do planejamento regional. A variabilidade das características socioespaciais territoriais pode ser constatada tanto no espaço urbano metropolitano quanto no espaço rural.

O espaço rural brasileiro é cenário multiescala de diversas situações conflitantes e atores sociais que incluem elementos da reforma agrária, da gestão dos recursos naturais, do agronegócio, da agricultura familiar e da simbiose entre o rural e urbano. No nordeste do país, destacam-se problemas relacionados à pobreza, à exclusão social, à degradação ambiental e às desigualdades sociais e econômicas num sentido amplo. Assim, para que se tenha uma política pública efetiva é necessário que esses aspectos sejam identificados, e que as políticas públicas territoriais reconheçam as diferenças internas que podem ocorrer no limite dos seus recortes, por exemplo, municipal, Território de Planejamento ou Território da Cidadania.

O município é a menor unidade político-administrativa no Brasil e, após a constituinte de 1988, desempenha papel importante no processo de descentralização das ações públicas. Os Territórios de Planejamento, formados por agregados de municípios do estado de Sergipe, existem desde 2007 e surgiram como meio de reforçar as identidades regionais e de otimizar as ações públicas estaduais. O Território da Cidadania surge, a partir de 2008, como uma nova dimensão na gestão de regiões rurais com forte presença da agricultura familiar e populações vulneráveis. Os Territórios da Cidadania compreendem conjuntos de municípios, que compartilham características comuns.

Diante dessas divisões regionais surge a questão da homogeneidade e da plausibilidade de uma única ação pública aplicada indiscriminadamente num município, num Território de Planejamento ou num Território da Cidadania de forma simétrica, sem considerar as particularidades locais. Afinal, serão essas assimetrias e 
heterogeneidades espaciais locais que determinarão o sucesso ou o fracasso das ações públicas, ainda que a avaliação de políticas públicas seja totalmente sensível a métricas de desempenho. Assim, faz-se necessário, para a construção de políticas territoriais de desenvolvimento, a elaboração de diagnósticos territoriais mais precisos e que levem em consideração aspectos locais das realidades territoriais.

Os diagnósticos territoriais compreendem a coleta, o processamento, a análise de dados e de informações sobre a realidade dos ambientes internos e externos dos territórios, servindo de base para elaboração de planos e priorização de projetos específicos para cada localidade (SABOURIN, 2002). Na elaboração de diagnósticos territoriais, a disponibilidade de informações estruturadas e organizadas aliada ao uso de ferramentas analíticas avançadas possibilita maior investigação dos territórios, ampliando a obtenção de conhecimento com valor agregado a respeito dessas unidades de planejamento. No estudo de recortes brasileiros, uma das ferramentas de análise bastante empregada são as técnicas multivariadas (CARVALHO, CRUZ e NOBRE, 1997; FIRETTI et al., 2010; SILVA, SIQUEIRA e TEIXEIRA, 2010). Essas técnicas têm se destacado devido a sua ampla capacidade de examinar múltiplas relações, proporcionando uma compreensão mais completa e realista dos indivíduos ou objetos sob investigação, fundamental nos processos de tomada de decisão (HAIR JR. et al., 2009).

Neste trabalho, duas técnicas de análise multivariada de dados foram utilizadas para avaliar características de moradia de domicílios rurais em diferentes recortes territoriais sergipanos (municípios, Territórios de Planejamento do Estado e Territórios da Cidadania): análise fatorial e análise de agrupamentos. A partir de dados do Censo Demográfico 2010, as seguintes características habitacionais foram avaliadas: condição de ocupação do domicílio; abastecimento de água; existência de banheiro ou sanitário; esgotamento sanitário; destino do lixo e energia elétrica.
Na seção seguinte serão apresentados os elementos da fundamentação teórica sobre o estudo territorial a partir da análise multivariada de dados. Em seguida, são detalhados os aspectos metodológicos do estudo, incluindo a seleção de variáveis e as técnicas de análise utilizadas. Os resultados e discussão serão apresentados logo na sequência, seguidos da conclusão.

\section{Fundamentação teórica}

\subsection{Análise territorial}

Há várias definições para o território, que pode ser tratado como um conceito abstrato ou como um objeto concreto dotado de características mensuráveis. O território pode ser definido como um espaço de construção histórica e social, de poder instituído (não imutável), caracterizado por recursos físicos (naturais e industriais) e valores (históricos e culturais), que estabelecem uma relação de identidade entre os habitantes que nele residem (TEIXEIRA, MELO e FRANÇA, 2011; SILVA, 2012). Também pode ser definido como uma unidade de referência, um nível de operação e agregação adequado para executar ações governamentais e políticas públicas capazes de promover mudanças e transformações múltiplas no espaço social (SCHNEIDER, 2004). Para o Ministério do Desenvolvimento Agrário (BRASIL, 2005, p. 7):

"[...] os territórios são definidos como um
espaço físico, geograficamente definido,
geralmente contínuo, compreendendo cida-
des e campos, caracterizado por critérios
multidimensionais, tais como o ambiente, a
economia, a sociedade, a cultura, a política e
as instituições, e uma população com grupos
sociais relativamente distintos, que se relacio-
nam interna e externamente por meio de pro-
cessos específicos, onde se pode distinguir um
ou mais elementos que indicam identidade e
coesão social, cultural e territorial."

Seja qual for a definição adotada, o sistema socioterritorial subjacente será dinâmico, 
complexo e com forte conexão entre o espaço e o social (SAQUET, 2010; SILVA et al., 2014; SILVA, 2015). Essas características dificultam o diagnóstico socioeconômico dos diferentes recortes territoriais usados na elaboração de políticas públicas, além de sugerirem que não se deve considerar um determinado recorte como pronto e definitivo. Estudos aprofundados são ainda mais necessários quando se constata que, frequentemente, há diferenças socioeconômicas intraterritoriais, conforme constatado por Wanderley (2014) num estudo de caso em dois Territórios da Cidadania nos estados de Pernambuco e Paraná. Portanto, a heterogeneidade espacial local é sem dúvida um fator relevante no processo de análise de dados geoespaciais agregados por área.

Para auxiliar no estudo dos diferentes recortes territoriais brasileiros, as técnicas multivariadas de análise de dados têm se tornado grandes aliadas, contribuindo com os processos de elaboração de políticas públicas com enfoque territorial (MOREIRA e TARGINO, 2002; SABOURIN, 2002). Na caracterização de recortes geográficos brasileiros, duas técnicas multivariadas têm se destacado: a análise fatorial e a análise de agrupamentos. Essas técnicas já foram utilizadas para traçar o perfil socioeconômico de microrregiões urbanas na região metropolitana do Rio de Janeiro a partir de variáveis associadas à estrutura e propriedade dos domicílios; saneamento; escolaridade; renda e demografia (CARVALHO, CRUZ e NOBRE, 1997). Além disso, foram aplicadas para traçar o perfil socioeconômico de beneficiários de programas assistencialistas em municípios paranaenses (PARANÁ, 2007).

Outros estudos envolvendo técnicas multivariadas foram baseados em levantamentos agropecuários. A partir de indicadores associados a atividades produtivas (área, estabelecimento, produção, renda, manejo e uso de recursos produtivos, dentre outros), as diferentes técnicas que empregam múltiplas variáveis foram utilizadas na obtenção de conhecimento a respeito de diferentes regiões brasileiras: na região Sul, visando construir uma tipologia dos municípios do Rio Grande do Sul (SCHNEIDER e WAQUIL, 2001); na região Sudeste, para identificar as principais atividades econômicas com potencial de geração de empregos e renda para trabalhadores rurais e pequenos produtores (FIRETTI et al., 2010); e, na região Nordeste, técnicas geocomputacionais de análise multivariada auxiliaram na identificação de três regimes espaciais locais distintos, no Território da Cidadania Sul Sergipano, a partir de dados agregados por município (SILVA, SIQUEIRA e TEIXEIRA, 2010).

\subsection{Territórios de Planejamento do estado de Sergipe}

Os Territórios de Planejamento do estado de Sergipe foram construídos, em 2007, com a sociedade, por meio de conferências locais, regionais e estaduais. Os municípios de cada Território de Planejamento foram agregados segundo suas similaridades históricas, econômicas, demográficas e geofísicas seguindo a definição territorial do MDA (BRASIL, 2005). Ao contrário dos Territórios da Cidadania, esses não têm um foco específico da agricultura familiar; aqui, o principal objetivo é auxiliar o planejamento estadual de forma holística. Sergipe, então, conta com oito Territórios de Planejamento: Agreste Central, Alto Sertão, Baixo São Francisco, Centro Sul, Grande Aracaju, Leste Sergipano, Médio Sertão e Sul Sergipano. $\mathrm{Na}$ maioria dos territórios sergipanos, mais de $50 \%$ da população economicamente ativa ocupa o setor primário (TEIXEIRA, MELO e FRANÇA, 2011).

Apesar do potencial de crescimento econômico do estado de Sergipe, cerca de $10 \%$ dos habitantes da área urbana e $28,9 \%$ da área rural vive na extrema pobreza, uma situação caracterizada por aspectos associados à renda da população e características domiciliares como, por exemplo, ausência de banheiro de uso exclusivo dos moradores; banheiros sem ligação com a rede geral de esgoto; domicílios de área urbana sem ligação à rede geral de distribuição de água; domicílios sem energia elétrica; dentre outros indicadores (SERGIPE, 2011). Tal situação realça a importância dos diagnósticos territoriais para a elaboração 
de políticas estruturadoras visando melhorias das condições de habitação dos sergipanos.

\subsection{Programa Territórios da Cidadania}

No Brasil, o modelo de desenvolvimento com enfoque territorial surgiu com o propósito de superar a visão localista seguida por seus municípios, cujos resultados mais evidentes eram a pulverização de recursos e a superposição de políticas públicas, resultando em um viés de fragilidade do processo de efetivação dessas políticas (LOPES e COSTA, 2009). Esse modelo tem sido apontado como uma estratégia diferenciada, quando comparada com os planos nacionais desenvolvimentistas da década de 1970, que busca promover a articulação e a gestão, descentralizada e participativa, de ações voltadas para o desenvolvimento social e sustentável das populaçóes, especialmente aquelas que vivem em áreas rurais brasileiras (BRASIL, 2007).

O Programa Territórios da Cidadania, iniciado em 2008, é coordenado pelo MDA mas congrega em sua proposta ações vinculadas a outros ministérios. No entanto, apesar do caráter universal da proposta, foi o perfil rural, a presença da agricultura familiar e os baixos níveis dos indicadores sociais como o Indice de Desenvolvimento Humano Municipal (IDHM) que formataram as composições dos 120 Territórios da Cidadania existentes hoje em todas as regiões do Brasil. Em Sergipe, tem-se quatro desses territórios: Alto
Sertão, Sertão Ocidental, Sul Sergipano e Baixo São Francisco. Apenas os Territórios do Alto Sertão e Baixo São Francisco coincidem em termos dos seus municípios componentes com os Territórios de Planejamento do Estado de Sergipe. Embora se motive a participação social nos processos de tomada de decisão nos colegiados e fóruns, os Territórios da Cidadania podem ser encarados como uma proposta do governo federal (BRASIL, 2009, 2010).

\section{Metodologia}

Neste trabalho foram analisados dados referentes a características habitacionais de domicílios rurais sergipanos, obtidos no levantamento do Censo Demográfico 2010 (Quadro 1). A base de dados analisada foi composta por 1.261 observações e 38 variáveis.

Cada variável apresentada no Quadro 1, com exceção das três primeiras, representa a proporção de uma característica habitacional avaliada (contagem da ocorrência do evento dividida pelo total de domicílios no setor rural). Com base nas proporções obtidas em cada setor, os dados foram examinados com relação à dispersão média, à distribuição normal, ao grau de associação entre as variáveis, à identificação de dados perdidos e à presença de observações atípicas. 


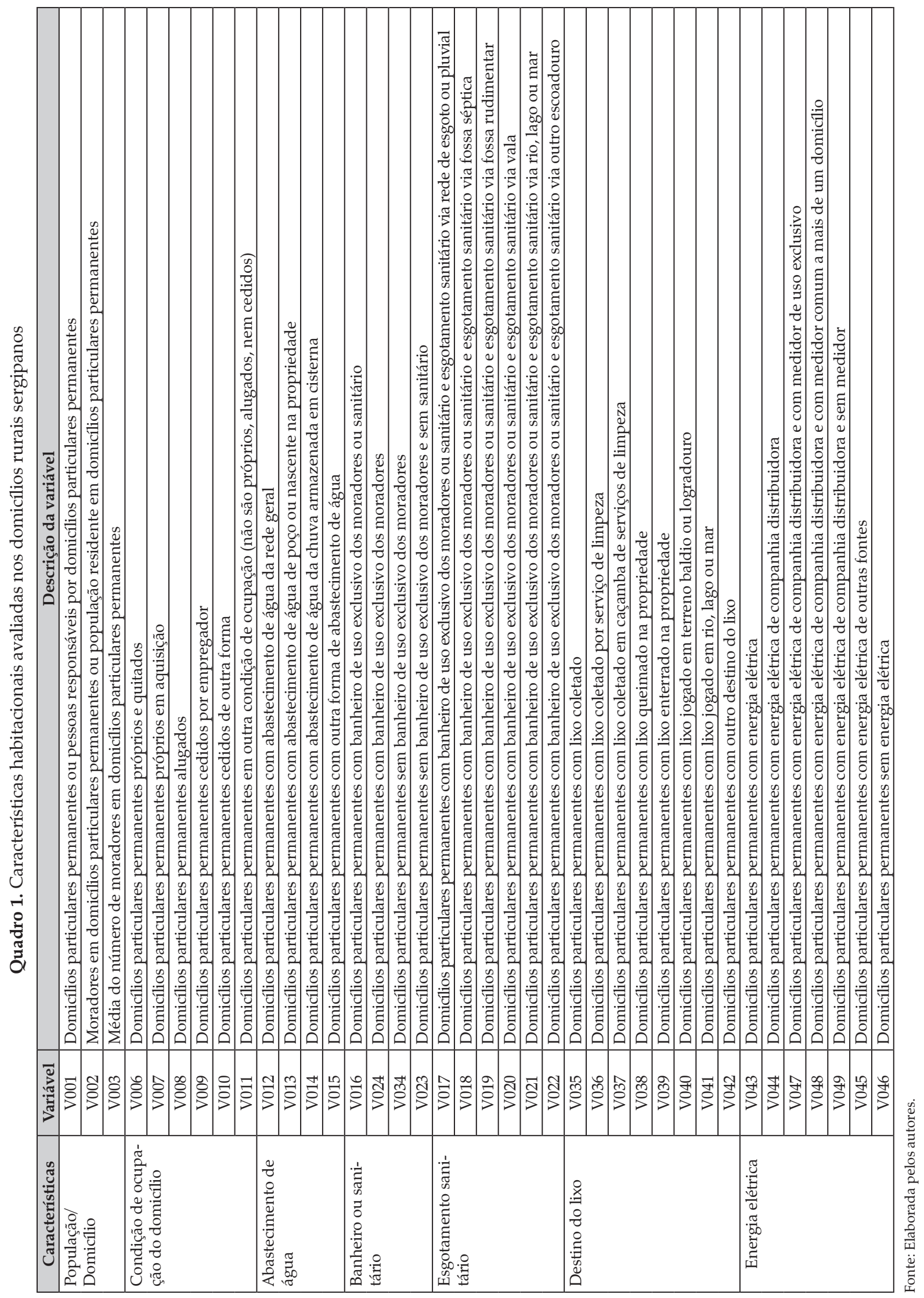


Além da análise prévia, os dados foram investigados através de técnicas de análise fatorial (método de componentes principais) e análise de agrupamentos (procedimentos hierárquico e não hierárquico). De modo geral, essas técnicas são utilizadas de forma combinada, possibilitando, em um primeiro momento, condensar a informação em um conjunto menor de variáveis (fatores), identificando a estrutura das relações existentes (HAIR JR. et al., 2009) e, em um segundo momento, caracterizar as informações apresentadas nos agregados (HASS e NEUMANM, 2010). A solução fatorial foi selecionada com base nas medidas de adequação da amostra individual (Measure of Sampling Adequacy - MSA), na avaliação conjunta das variáveis (critério de Kaiser Meyer Olkin - KMO) e na significância geral da matriz de correlação (teste de Bartlett). Para auxiliar na interpretação dos resultados foi utilizado o método Varimax, um dos mais empregados para obtenção de uma estrutura fatorial simplificada. Os métodos Ward e K-Média foram utilizados na construção dos agregados. Para medir as similaridades entre os objetos investigados foi utilizada a distância euclidiana.

As técnicas de análise discriminante e visualização de dados foram utilizadas para auxiliar na caracterização dos recortes territoriais sergipanos. Posteriormente, foram obtidas amostras da base de dados estudada para validação dos resultados. O processo de identificação de observações atípicas continuou durante a aplicação das técnicas multivariadas.

\section{Resultados e discussão}

Na etapa de análise prévia, foi observado que os dados examinados não apresentavam distribuição normal. Com relação à presença de observações atípicas (erros de codificação, observações isoladas, observações com valores diferentes das demais etc.), as mudanças não foram significativas após a remoção dos registros com essas características, situação mantida durante a aplicação das técnicas multivariadas.

Ainda na etapa inicial, foram realizadas análises para avaliar a força da correlação entre as variáveis e o tipo da associação (positiva ou negativa). Através da inspeção visual da matriz de correlação, as variáveis significativas foram pré-selecionadas e submetidas ao teste de adequação para uso da técnica de análise fatorial. Essa técnica possibilita identificar a estrutura presente no conjunto de varáveis a partir das correlações existentes e, ao mesmo tempo, promove a redução dos dados, em que estes podem ser representados por um número menor de variáveis compostas (HAIR JR. et al., 2009). Nessa perspectiva, diferentes características habitacionais de áreas rurais sergipanas foram avaliadas visando identificar um padrão de moradia nos territórios do estado.

Do conjunto total de variáveis investigadas, oito foram selecionadas para compor a solução fatorial (Tabela 1). Essas variáveis apresentaram medidas de adequação individual $(M S A)$ e geral (KMO) significativas (valores acima de 0,50$)$. Outro

Tabela 1. Avaliação da adequação à técnica de análise fatorial: medidas de adequação da amostra e correlações parciais entre as variáveis

\begin{tabular}{|c|c|c|c|c|c|c|c|c|}
\hline & V006 & V009 & V016 & V034 & V036 & V038 & V047 & V049 \\
\hline V006 & $690^{a}$ & 679 & ,047 &,- 043 & ,019 &,- 061 &,- 069 & ,032 \\
\hline V009 & 679 & $665^{a}$ & ,000 &, 002 & ,072 &,- 084 & ,174 &,- 103 \\
\hline V016 & ,047 & ,000 &, $721^{a}$ & ,554 &,- 076 &, 054 &,- 083 &,- 011 \\
\hline V034 &,- 043 & ,002 & ,554 &, $718^{\mathrm{a}}$ & ,018 &,- 113 & ,009 &,- 016 \\
\hline V036 & ,019 & ,072 &,- 076 & ,018 & $626^{a}$ & 766 & ,038 & ,019 \\
\hline V038 &,- 061 &,- 084 & ,054 &,- 113 & ,766 & $621^{a}$ & ,041 & ,068 \\
\hline V047 &,- 069 & 174 &,- 083 & ,009 & ,038 & ,041 & ,729a & 609, \\
\hline V049 & ,032 &,- 103 &,- 011 &,- 016 & 0,19 & ,068 & 609 & $626^{a}$ \\
\hline
\end{tabular}

(a) Medida de adequação da amostra para cada variável (MSA) - valores na diagonal principal.

Correlações parciais (demais valores não selecionados).

Critério de Kaiser Meyer Olki (KMO): 0,67.

Teste de Bartlett: 0,00.

Fonte: Elaborada pelos autores. 
Tabela 2. Resultados obtidos através do método de componentes principais

\begin{tabular}{c|ccc|ccc}
\hline \multirow{2}{*}{ Componentes } & \multicolumn{3}{|c|}{ Não rotacionado } & \multicolumn{3}{c}{ Rotacionado (Varimax) } \\
\cline { 2 - 7 } & Autovalor & Variância (\%) & $\begin{array}{c}\text { Variância } \\
\text { Acumulada (\%) }\end{array}$ & Autovalor & Variância (\%) & $\begin{array}{c}\text { Variância } \\
\text { Acumulada (\%) }\end{array}$ \\
\hline 1 & 2,902 & 36,274 & 36,274 & 2,665 & 33,316 & 31,316 \\
2 & 2,276 & 28,445 & 64,719 & 2,512 & & \\
3 & 1,031 & 12,894 & 77,613 & & \\
4 &, 710 & 8,878 & 86,491 & & \\
5 &, 354 & 4,423 & 90,914 & & \\
6 &, 321 & 4,008 & 94,922 & & & \\
7 &, 224 & 2,801 & 97,723 & & & \\
8 &, 182 & 2,277 & 100,000 & & & \\
\hline
\end{tabular}

Fonte: Elaborada pelos autores.

Tabela 3. Matrizes de cargas fatoriais rotacionadas (método Varimax).

\begin{tabular}{cccc}
\hline \multicolumn{4}{c}{ (a) } \\
\hline \multirow{2}{*}{ Variável } & \multicolumn{2}{c}{ Cargas Fatoriais } & \multirow{2}{*}{ Comunalidade } \\
\cline { 2 - 3 } & Fator 1 & Fator 2 & \\
\hline V006 &, 831 &, 044 &, 693 \\
V009 &,- 853 &, 090 &, 736 \\
V047 &, 818 &,- 138 &, 688 \\
V049 &,- 754 &, 010 &, 568 \\
V016 &, 048 &,- 746 &, 559 \\
V034 &,- 018 &, 747 &, 559 \\
V036 &, 067 &,- 820 &, 677 \\
V038 &,- 046 &, 834 &, 698 \\
Variância \% & $\mathbf{3 3 , 3 1 6}$ & $\mathbf{3 1 , 4 0 3}$ & $\mathbf{6 4 , 7 1 9}$ \\
\hline
\end{tabular}

\begin{tabular}{cccc}
\hline \multicolumn{4}{c}{$(\mathbf{b})$} \\
\hline \multirow{2}{*}{ Variável } & \multicolumn{2}{c}{ Cargas Fatoriais } & \multirow{2}{*}{ Comunalidade } \\
\cline { 2 - 3 } & Fator 1 & Fator 2 &, 693 \\
V006 &, 831 &, 044 &, 736 \\
V009 &,- 853 &, 090 &, 688 \\
V047 &, 818 &,- 138 &, 568 \\
V049 &,- 754 &, 010 &, 559 \\
V023 &,- 048 &, 746 &, 559 \\
V024 &, 018 &,- 747 &, 677 \\
V036 &, 067 &,- 820 &, 698 \\
V038 &,- 046 &, 834 & 64,719 \\
Variância \% & 33,316 & $\mathbf{3 1 , 4 0 3}$ &
\end{tabular}

Fonte: Elaborada pelos autores.

resultado positivo foi o teste de Bartlett (sig. <0,05), indicando que há correlações suficientes entre as variáveis para proceder com a análise fatorial.

De acordo com os resultados, os dois primeiros fatores foram selecionados para representar o conjunto reduzido de variáveis (Tabela 2). A solução apresentou autovalores acima de um e cargas significativas após a rotação dos fatores pelo método Varimax, explicando aproximadamente $65 \%$ da variância total dos dados $(33 \%$ e $31 \%$ para cada fator respectivamente). Na Tabela 3 são apresentadas as cargas fatoriais, medidas que representam a contribuição das variáveis na composição dos fatores, seguida das respectivas comunalidades (quantia total de variância que uma variável compartilha com todas as outras variáveis da análise).

De acordo com as cargas fatoriais apresentadas no primeiro fator (Tabela 3a), houve uma associação direta entre as variáveis domicílios próprios e quitados (V006) e domicílios com energia elétrica de companhia distribuidora e medidor de consumo de energia de uso exclusivo dos moradores (V047). Essas variáveis variam juntas e se movem no mesmo sentido (sinais iguais). Ainda na análise do primeiro fator, foi possível observar uma relação direta entre os domicílios cedidos por empregador (V009) e domicílios que possuem energia elétrica; porém, sem medidor de consumo de energia (V049).

No segundo fator (Tabela 3a), foi observada uma associação direta (mesmo sinal) entre os domicílios que possuem banheiro de uso exclusivo dos moradores ou sanitário ${ }^{4}$ (V016)

4. O IBGE considera como banheiro o cômodo que tenha chuveiro (ou banheira) e vaso sanitário (ou privada), de uso exclusivo dos moradores, inclusive os localizados no terreno ou na propriedade (IBGE, 2011). No caso da variável V016, estão contemplados tanto os domicílios com banheiro completo quanto os domicílios que possuem apenas sanitários de uso exclusivo ou não dos moradores. 
Tabela 4. Resultados das análises de agrupamentos

\begin{tabular}{ccccccccccccccc}
\hline Grupo & V006 & V009 & V016 & V023 & V024 & V034 & V036 & V038 & V043 & V044 & V047 & V049 & \% Habitantes & N \\
\hline 1 & 0,855 & 0,021 & 0,968 & 0,032 & 0,892 & 0,108 & 0,871 & 0,088 & 0,985 & 0,976 & 0,919 & 0,026 & 28,35 & 332 \\
2 & 0,831 & 0,055 & 0,920 & 0,080 & 0,801 & 0,199 & 0,247 & 0,360 & 0,972 & 0,965 & 0,874 & 0,042 & 22,21 & 278 \\
3 & 0,841 & 0,062 & 0,847 & 0,153 & 0,693 & 0,307 & 0,035 & 0,821 & 0,970 & 0,967 & 0,882 & 0,032 & 49,43 & 651 \\
\hline
\end{tabular}

Fonte: Elaborada pelos autores.

e domicílios onde o lixo é coletado por serviços de limpeza (V036). Continuando com a interpretação desse fator, houve uma associação direta entre os domicílios com banheiros compartilhados (V034) e domicílios que realizam a queima do lixo na propriedade (V038).

Segundo Miranda e Costa (2009), o estado de Sergipe apresenta elevados índices de domicílios sem banheiro, principalmente nas pequenas cidades localizadas em espaços rurais. Com o interesse de identificar uma estrutura correlacional entre essa variável e as demais, uma segunda matriz foi gerada ${ }^{5}$ (Tabela $3 b$ ). De acordo com os resultados obtidos, os domicílios sem banheiro e sem sanitário (V023) estão diretamente associados aos domicílios que praticam a queima do lixo na propriedade (V038). Já os domicílios com banheiro de uso exclusivo dos moradores (V024) apresentaram correlações diretas e significativas com os domicílios onde há serviços de coleta de lixo (V036).

O estudo prosseguiu com a análise de agrupamentos visando identificar agregados de setores censitários rurais sergipanos com características similares de moradia. Nessa técnica, as suposições estatísticas não são relevantes como na análise fatorial (HAIR JR. et al., 2009). Os agrupamentos foram construídos a partir do conjunto reduzido de variáveis (Tabela $3 a$ e $3 b$ ). As soluções compostas por três grupos apresentaram os melhores resultados: variáveis significativas; grupos balanceados e maior proximidade das médias e do número de observações por agregados (comparação dos resultados obtidos através dos procedimentos hierárquico e não hierárquico). Na Tabela 4 é apresentado o comportamento das

5. As variáveis V024 e V034 não foram incluídas no mesmo modelo (são opostas e apresenta uma correlação igual a 1). variáveis pré-selecionadas na análise fatorial ${ }^{6}$. O primeiro agregado apresentou maior percentual médio de domicílios próprios e quitados (V006), com banheiro de uso exclusivo dos moradores (V024), serviço de coleta de lixo (V036), energia elétrica de companhia distribuidora e medidor de consumo de energia de uso exclusivo (V047). Já no terceiro agregado, os percentuais médios de domicílios sem banheiro e sem sanitário (V023); sem banheiro de uso exclusivo dos moradores (V034) e que realizam a queima do lixo na propriedade (V038) foram mais elevados.

De acordo com a Tabela 4, as características habitacionais associadas à condição de ocupação do domicílio (próprio e quitado) e energia elétrica apresentaram percentuais médios superiores a $80 \%$ nos três grupos formados (V006, V043, V044 e V047). As características associadas ao cômodo banheiro e ao destino do lixo proporcionaram maior diferenciação dos grupos. Com relação à composição dos agrupamentos, o terceiro grupo apresentou maior número de setores censitários rurais e maior percentual de habitantes. Na Figura 1 é apresentado o mapa de setores censitários rurais do estado de Sergipe, construído a partir da solução de três agrupamentos, seguido da caracterização dos domicílios rurais nos recortes municipais, Territórios de Planejamento do Estado e Territórios da Cidadania.

6. Embora os agrupamentos tenham sido construídos com um conjunto reduzido de variáveis (Tabelas 3a e 3b), o comportamento de outras variáveis também foram investigados nos agregados. A análise fatorial é um ponto de partida para o uso de outras técnicas multivariadas. As variáveis poderiam ser sugeridas por especialistas sem a necessidade da análise fatorial. No entanto, essa técnica auxiliou na identificação de estruturas presente no conjunto de dados estudado. 
Figura 1. Agrupamentos de setores censitários rurais sergipanos por características habitacionais

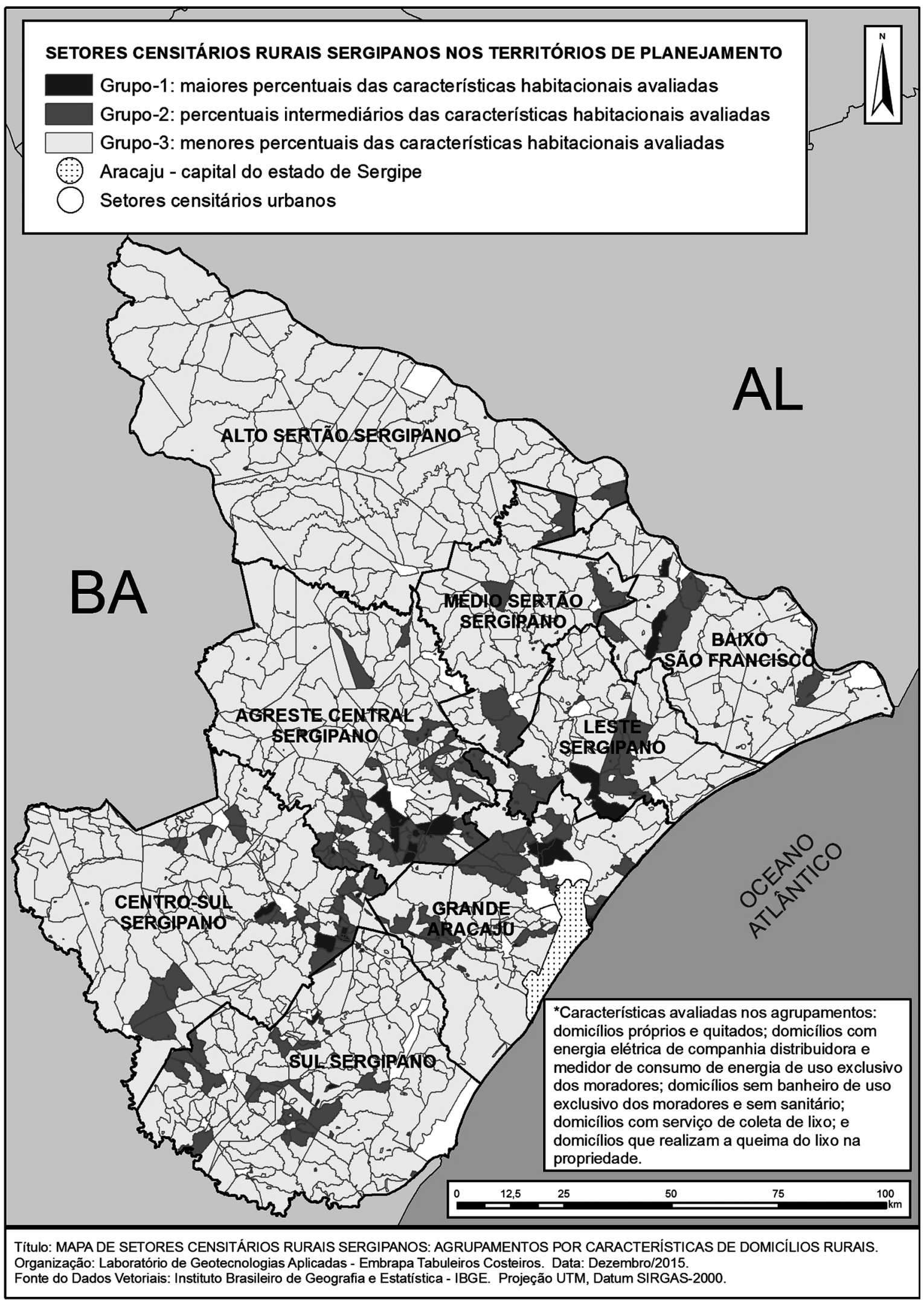


De modo geral, no recorte municipal sergipano foram identificados setores rurais dos três agrupamentos (Figura 2). Na maioria dos municípios houve maior número de setores associados ao terceiro grupo (maior percentual médio de domicílios sem banheiro de uso exclusivo dos moradores e sem sanitário; e de domicílios que realizam a queima do lixo em suas propriedades). Alguns municípios apresentaram características de um único agregado como, por exemplo, Amparo de São Francisco, Feira Nova e Monte Alegre (todos pertencentes ao terceiro grupo) e o município de São Francisco, apenas com setores rurais do primeiro grupo. O município de Aracaju, capital do estado, não foi incluído na análise.
O estado de Sergipe é formado por pequenas cidades em espaços rurais (ou pequenos centros urbanos) consolidados, com frágil ou pouco grau de dinamismo; com pouca densidade econômica e que apresenta elevado grau de desigualdade e pobreza (BRASIL, 2009). Em levantamentos realizados no estado, o déficit habitacional não foi considerado elevado (em números absolutos); porém, as inadequações habitacionais atingiram níveis alarmantes (MIRANDA e COSTA, 2009). Os domicílios sergipanos enfrentam problemas de ausência de banheiro, esgotamento sanitário, abastecimento de água, dentre outros entraves que afetam as condições de vida da população (SERGIPE, 2011).

Figura 2. Agrupamentos de setores censitários rurais em recortes municipais sergipano

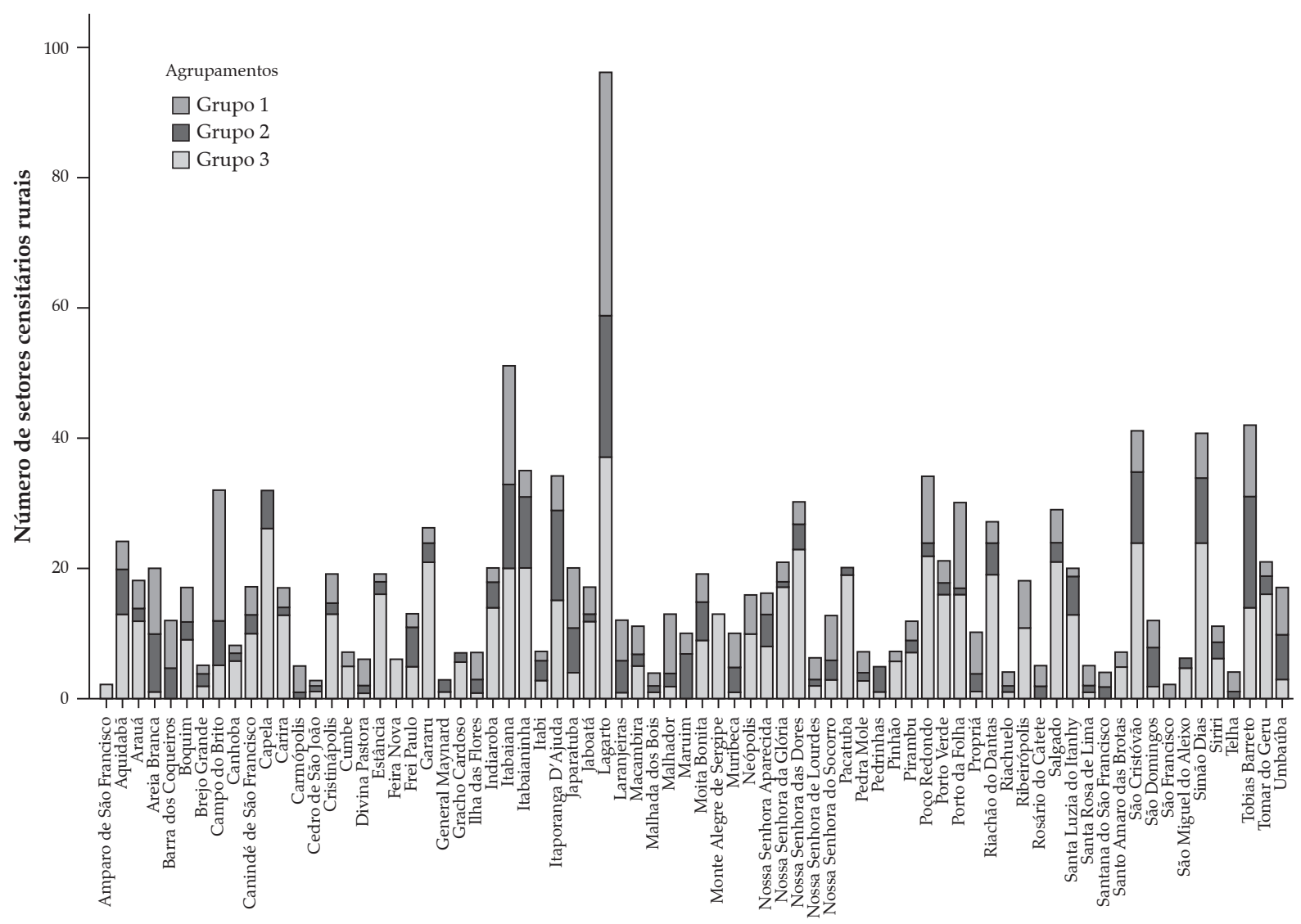

Municípios Sergipanos 
$\mathrm{Na}$ análise do recorte municipal (Figura 2), a maioria dos setores rurais apresentou percentuais acima de $60 \%$ de domicílios próprios e quitados. Nos municípios de Capela, Tomar do Geru e Riachão do Dantas foram identificados setores rurais onde mais de $70 \%$ dos domicílios não pos- suíam banheiro. Na avaliação dos Territórios de Planejamento do estado de Sergipe e da Cidadania (Figuras 3 e 4 respectivamente), houve destaque maior para os setores rurais do terceiro grupo (condições menos favoráveis, principalmente com relação aos indicadores de existência de banheiro).

Figura 3. Agrupamentos de setores censitários rurais nos Territórios de Planejamento do estado de Sergipe

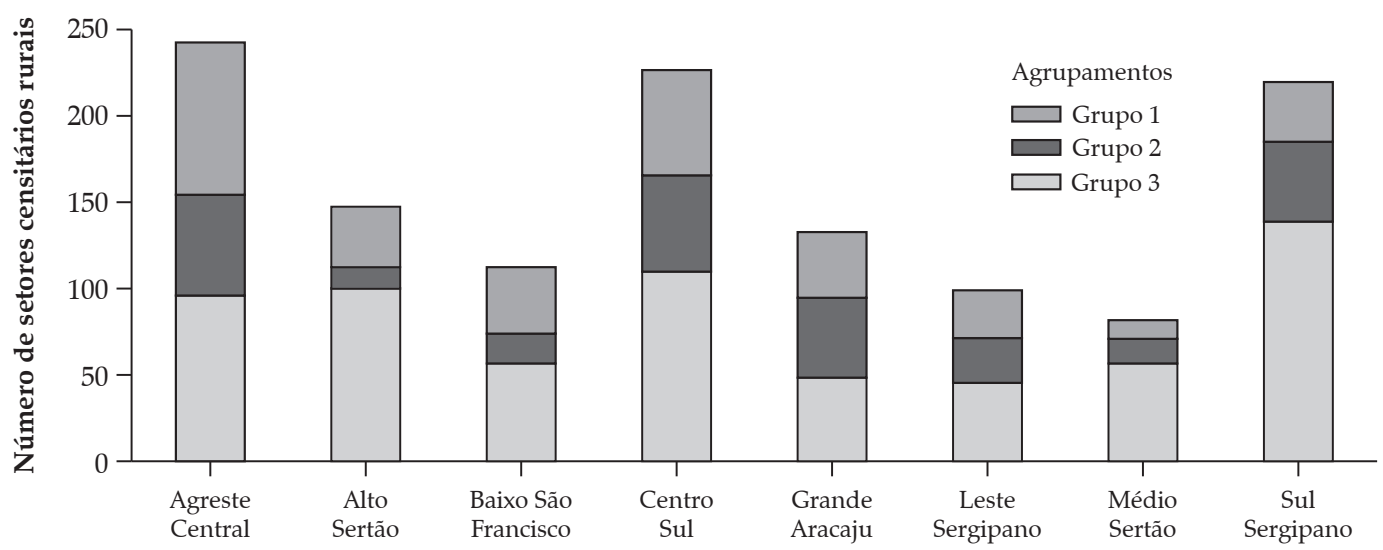

Territórios de Planejamento do estado de Sergipe

Fonte: Elaborada pelos autores.

Figura 4. Agrupamentos de setores censitários rurais nos Territórios da Cidadania do estado de Sergipe

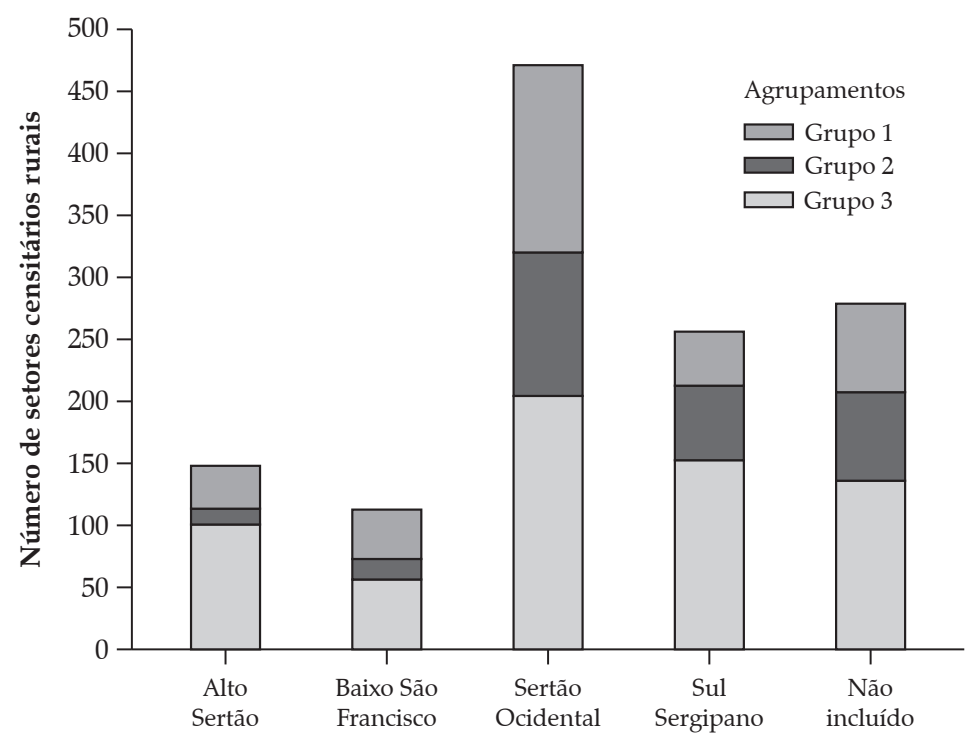

Territórios da Cidadania no estado de Sergipe e recorte não incluído

Fonte: Elaborada pelos autores. 
Figura 5. Agrupamentos de setores censitários rurais nos Territórios de Planejamento do estado de Sergipe: condição de ocupação do domicílio e energia elétrica

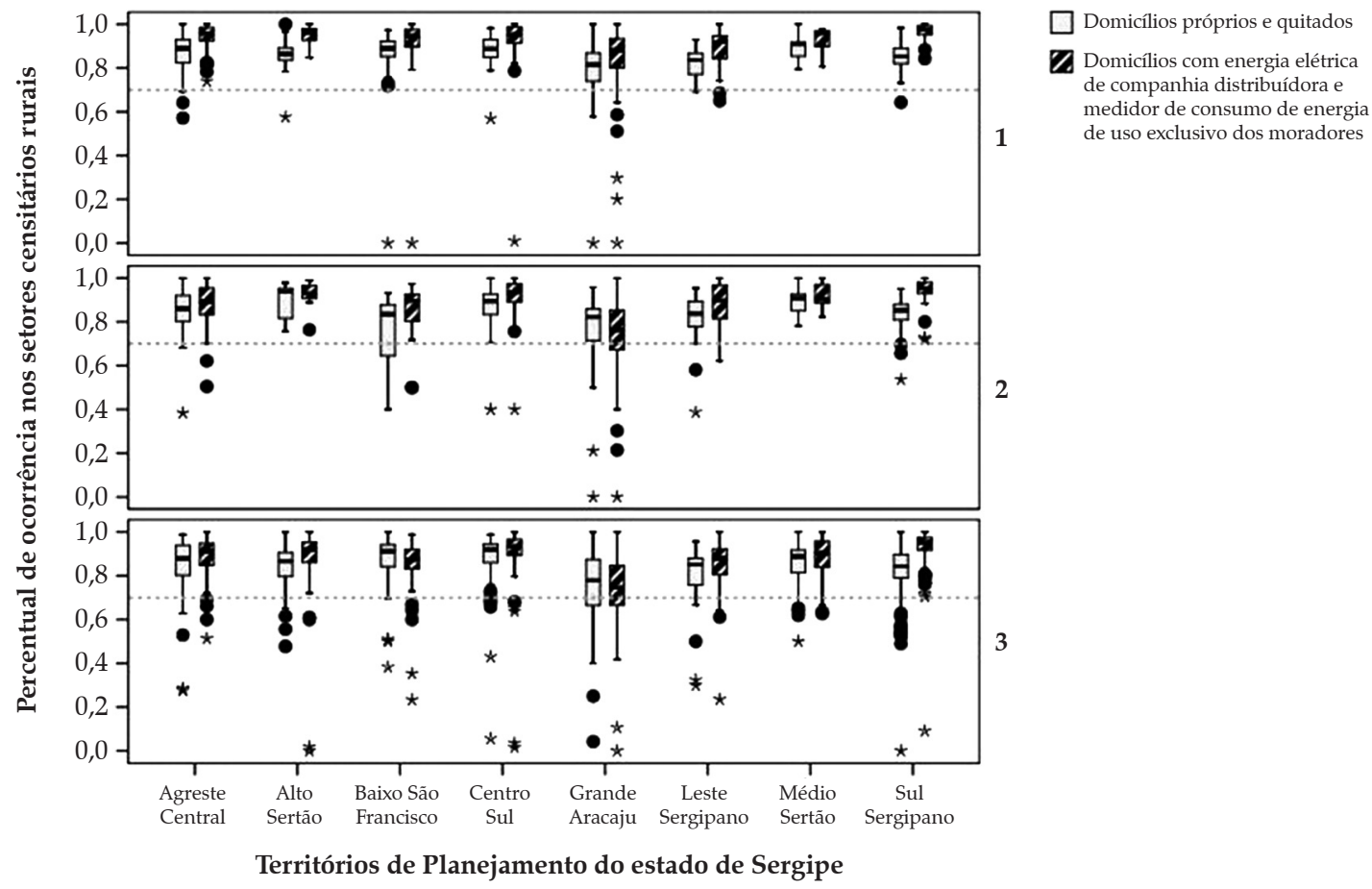

Fonte: Elaborada pelos autores.

No Agreste Central e na Grande Aracaju (Figura 3), foram observados grupos mais equilibrados, enquanto que no Sul Sergipano houve proporção maior de setores do terceiro agrupamento. Em todas as regiões do estado, em levantamentos anteriores, foram identificados municípios com elevado grau de desigualdade e pobreza (BRASIL, 2009). Nesses municípios, 45\% da população residiam em áreas rurais; possuíam número maior de domicílios sem banheiro e um alto déficit habitacional relativo (MIRANDA e COSTA, 2009; SERGIPE, 2011). Com base na avaliação conjunta das variáveis, além do cômodo banheiro, o destino do lixo foi outra questão problemática evidenciada nesse estudo. Esse comportamento foi observado inclusive na Grande Aracaju, caracterizado por apresentar melhores condições de infraestrutura e no recorte não incluído nos Territórios da Cidadania (Figura 4).
Nos gráficos de caixa ${ }^{7}$ (Box Plot) são apresentadas as proporções de ocorrência de cada característica habitacional avaliada nos setores rurais sergipanos. Em todos os recortes dos Territórios de Planejamento do estado de Sergipe (Figuras 5), as distribuições de domicílios próprios e quitados; com energia elétrica de companhia distribuidora e medidor de consumo de energia foram menores no primeiro agrupamento. Nesse agregado, os percentuais foram bastante expressivos (salvos os valores atípicos ou extremos, os

7. Nesse gráfico, a caixa contém $50 \%$ dos valores centrais dos dados. Quanto maior a caixa, maior a dispersão das observações (distribuição dos dados). A linha horizontal dentro de cada caixa indica a mediana; a linha vertical indica desvios acima da média; o ponto indica dados atípicos e o asterisco indica valores extremos. Para facilitar a interpretação das variáveis por agregados, foi inserida uma linha horizontal tracejada. 
dados estavam concentrados na região do gráfico superior a $70 \%$ ).

Nos recortes da Grande Aracaju (Figura 5) e no recorte não incluído nos Territórios da Cidadania (Figura 6), as distribuições percentuais foram maiores, sinalizando para a existência de setores menos favoráveis com relação à condição de ocupação do domicílio (próprio e quitado) e energia elétrica.

Nas análises dos indicadores de presença de banheiro (Figuras 7 e 8 respectivamente), os setores rurais do primeiro grupo apresentaram melhores resultados: maiores percentuais de domicílios com banheiro de uso exclusivo dos moradores e maiores percentuais de domicílios com serviço de coleta de lixo. Para essa última variável, no terceiro agrupamento, a distribuição dos dados nos recortes foi relativamente baixa (valores abaixo de 30\%) sinalizando que os serviços de coleta de lixo são menos frequentes em áreas rurais pertencentes a esse agregado quando comparado aos demais grupos.

Com relação à disponibilidade de banheiro de uso exclusivo dos moradores (Figuras 7 e 8 respectivamente), a maior distribuição dos dados ocorreu principalmente no terceiro agrupamento. De modo geral, os setores apresentaram percentuais acima de $60 \%$. O compartilhamento do cômodo banheiro ainda é uma realidade de várias residências rurais sergipanas. Quanto ao indicador de ausência de banheiro e sanitário (Figuras 9 e 10 respectivamente), principalmente no terceiro agrupamento, foram identificados setores rurais onde mais de $20 \%$ dos domicílios são desprovidos desse indicador.

Figura 6. Agrupamentos de setores censitários rurais nos Territórios da Cidadania do estado de Sergipe: condição de ocupação do domicílio e energia elétrica

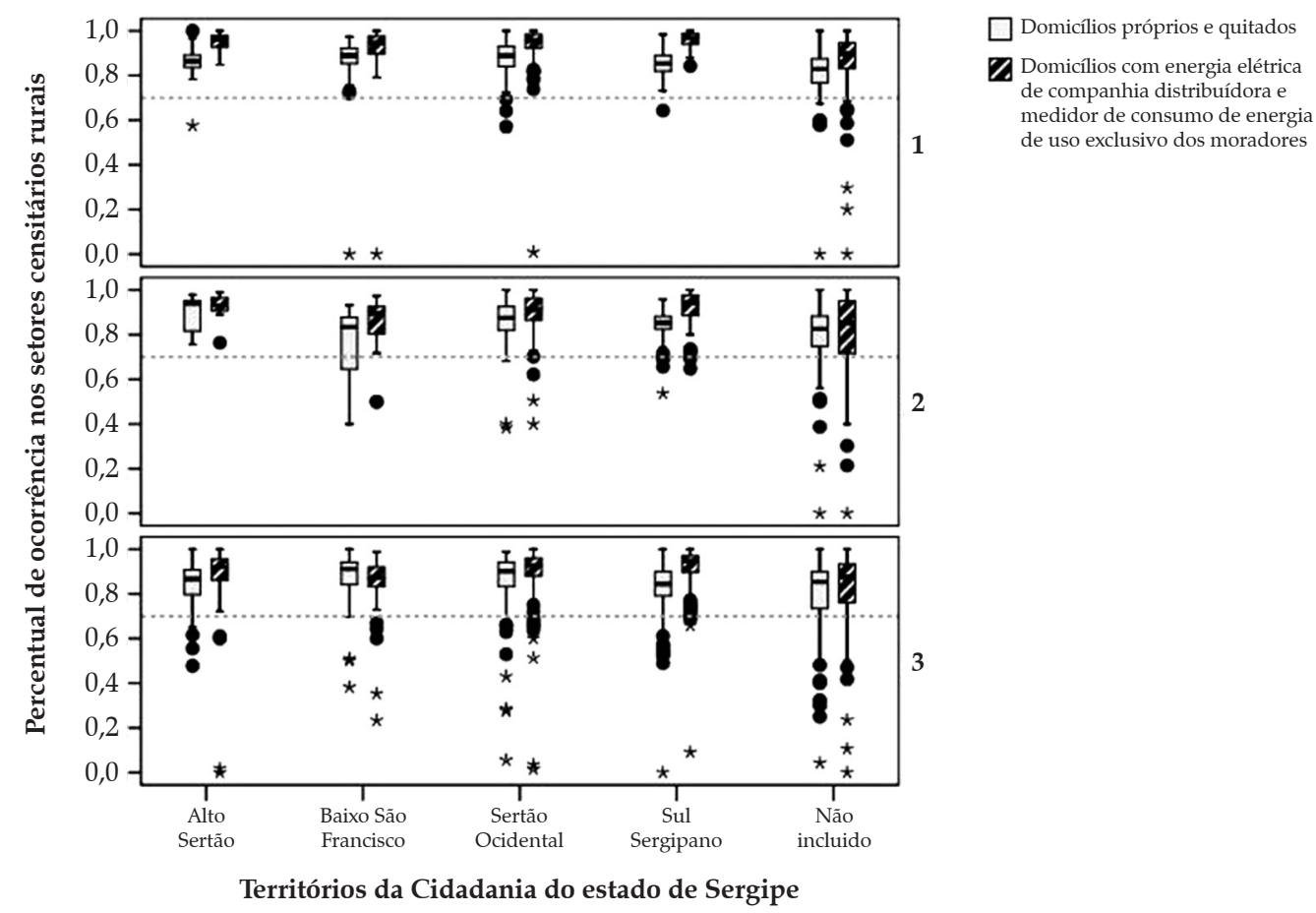

Fonte: Elaborada pelos autores. 
Figura 7. Agrupamentos de setores censitários rurais nos Territórios de Planejamento do estado de Sergipe: indicador da presença de banheiro exclusivo e destino do lixo

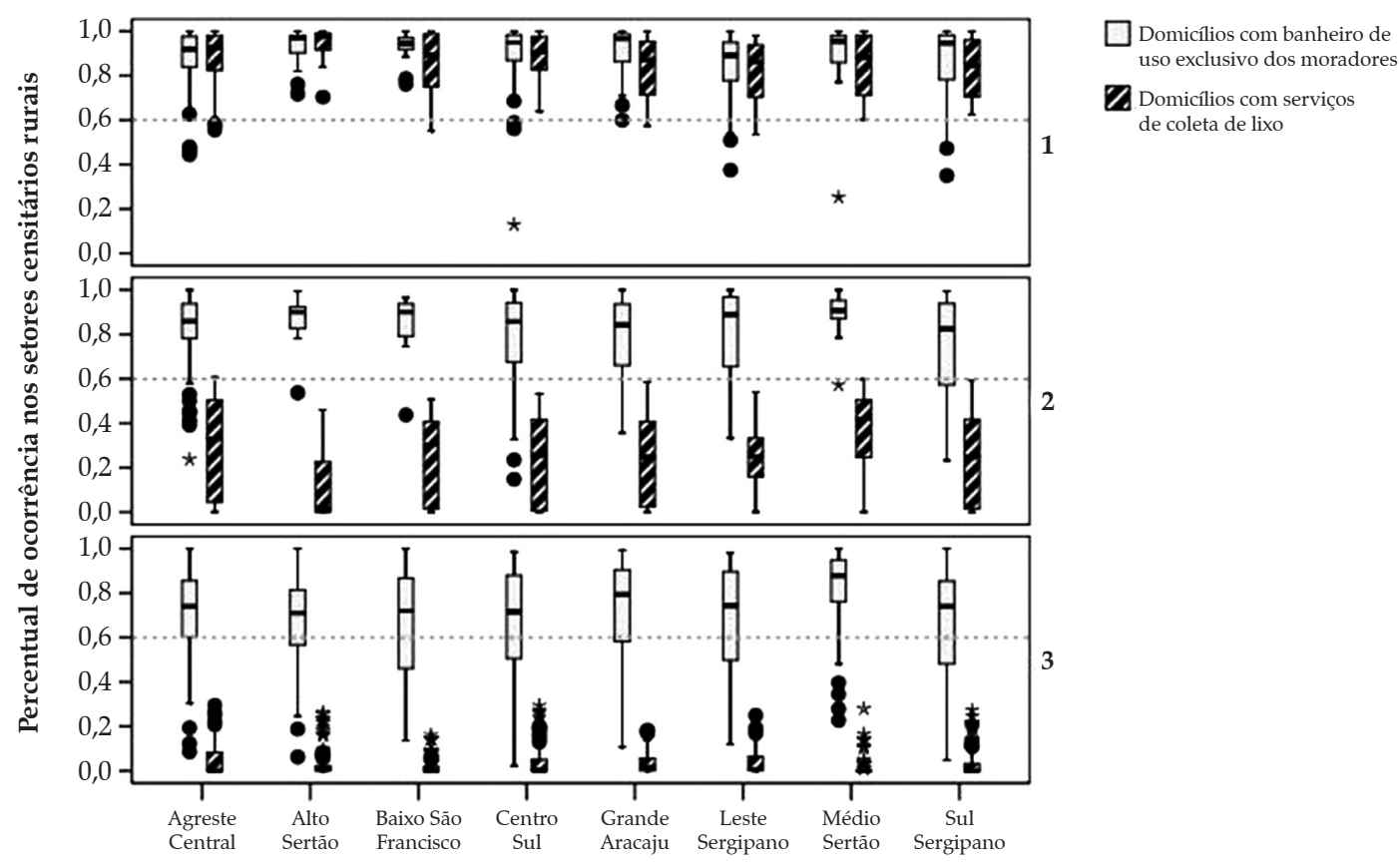

Territórios de Planejamento do estado de Sergipe

Fonte: Elaborada pelos autores.

Figura 8. Agrupamentos de setores censitários rurais nos Territórios da Cidadania de Sergipe: indicador da presença de banheiro exclusivo e destino do lixo

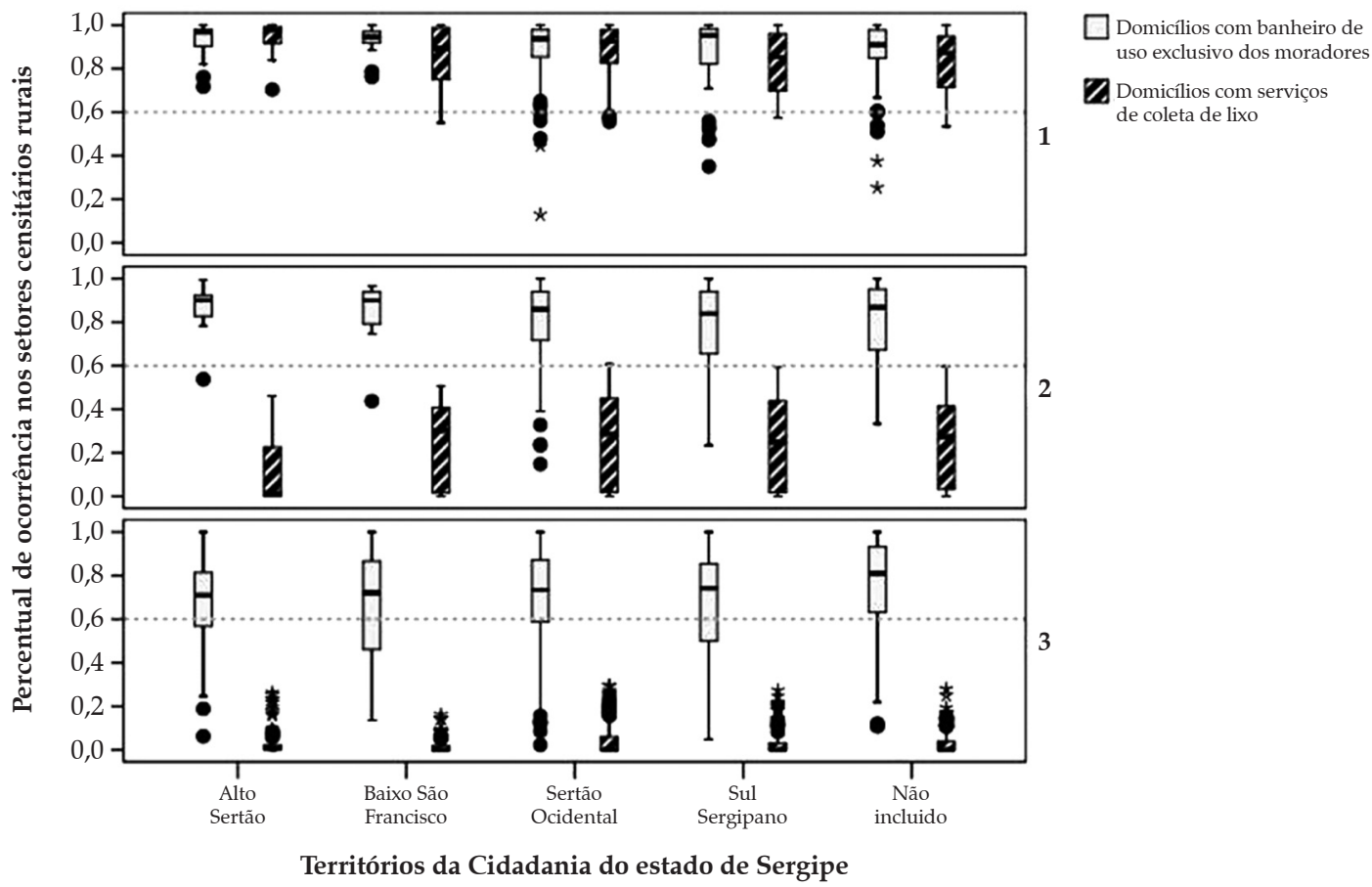

Fonte: Elaborada pelos autores. 
Figura 9. Agrupamentos de setores censitários rurais nos Territórios de Planejamento do estado de Sergipe: destino do lixo e indicador de ausência de banheiro e sanitário

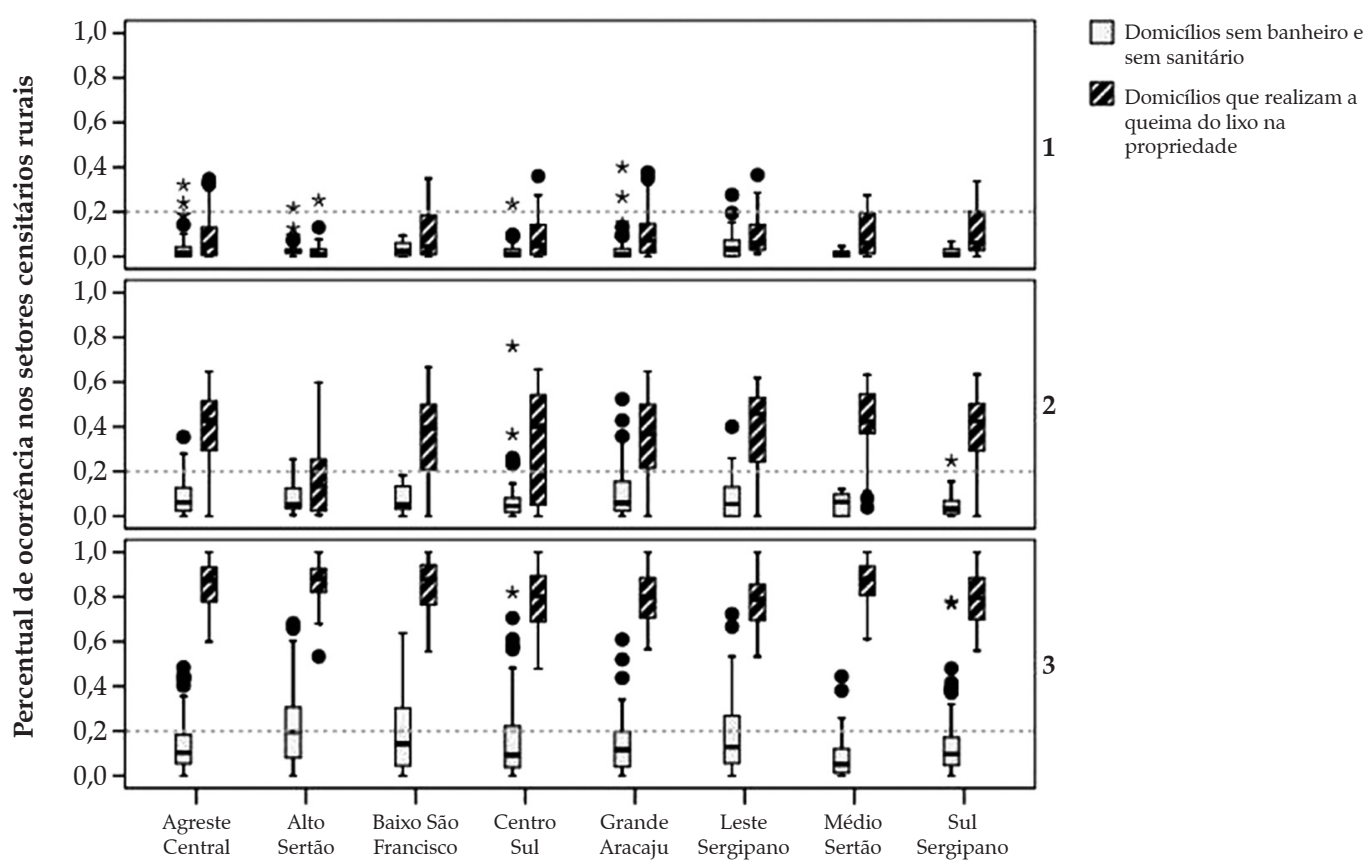

Territórios de Planejamento do estado de Sergipe

Fonte: Elaborada pelos autores.

Figura 10. Agrupamentos de setores censitários rurais nos Territórios da Cidadania do estado de Sergipe: destino do lixo e indicador de ausência de banheiro e sanitário

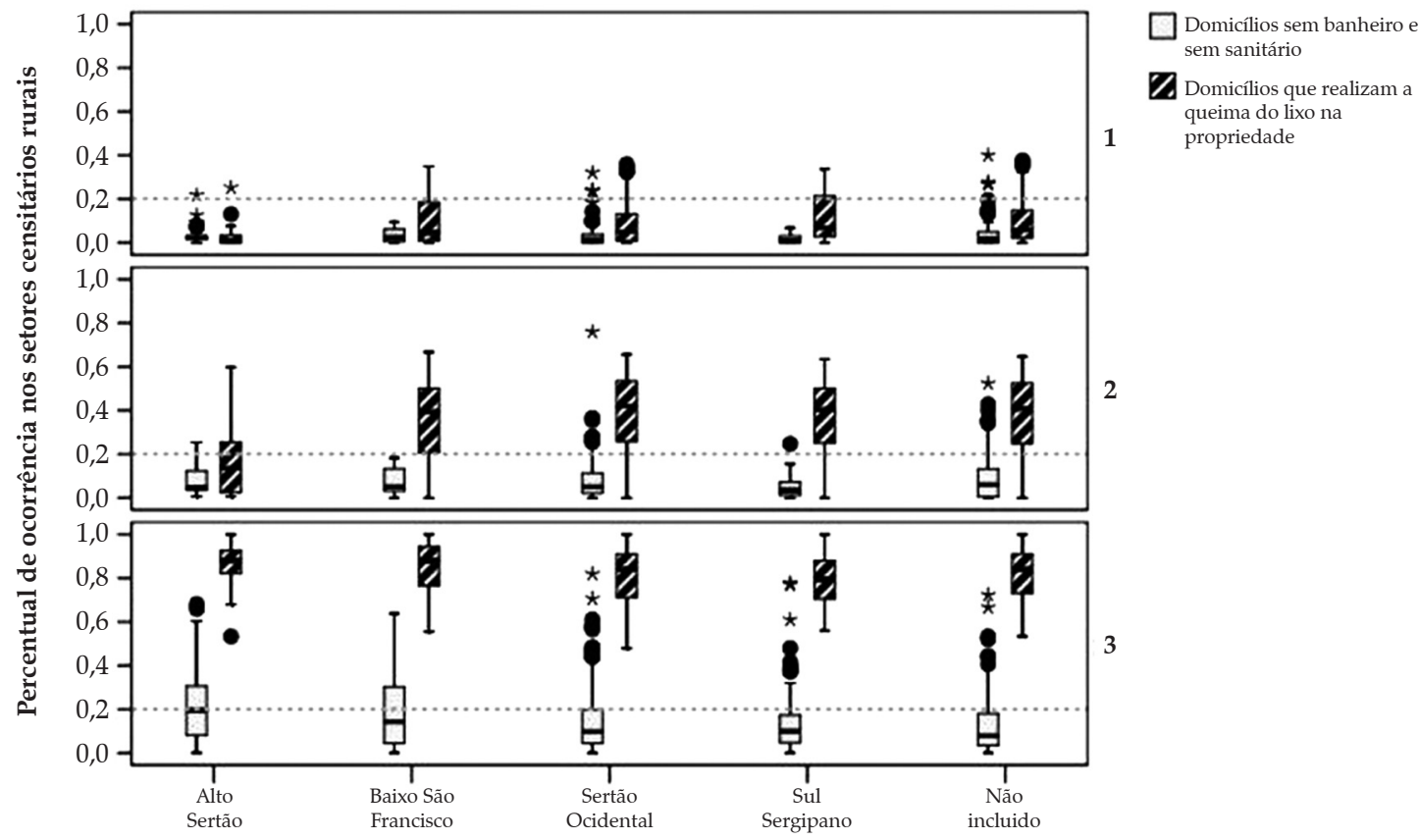

Territórios da Cidadania do estado de Sergipe

Fonte: Elaborada pelos autores. 
Na situação apresentada (Figuras 9 e 10), os domicílios rurais não dispunham nem mesmo de instalações compartilhadas onde os moradores pudessem dispor seus dejetos. Esse é um problema bastante preocupante para o Estado, necessitando de atenção especial de programas assistencialistas, caso o modelo teórico se confirme na prática. Também foi observado que, no terceiro agrupamento, os percentuais de domicílios que realizam a queima do lixo na propriedade foram mais elevados (valores concentrados acima de $70 \%$ ).

A distribuição dos percentuais de ocorrência possibilitou identificar áreas rurais sergipanas com condições domiciliares mais problemáticas ou que se destacaram por apresentar melhores condições de moradia. No recorte da Grande Aracaju, por exemplo, as maiores dispersões percentuais de domicílios próprios e quitados; e domicílios com energia elétrica e medidor de consumo de energia de uso exclusivo dos moradores sinalizaram para existência de áreas rurais que merecem uma maior atenção do Estado. Essa situação também foi identificada no recorte sergipano não incluído nos Territórios da Cidadania.

Por outro lado, no recorte do Médio Sertão Sergipano, os baixos percentuais associados ao indicador que trata da ausência de banheiro e sanitário revelaram que, nesse recorte, essa caracterís- tica habitacional não foi tão problemática quando comparada aos demais recortes do estado.

$\mathrm{Na}$ avaliação da dimensão abastecimento de água e esgotamento sanitário, as variáveis estudadas não foram significativas para o uso conjunto de técnicas multivariadas (análise fatorial e análise de agrupamentos). Como essas variáveis são importantes na definição de estratégias de políticas públicas, foi realizada uma análise da distribuição da ocorrência das mesmas nos Territórios de Planejamento do Estado e nos Territórios da Cidadania. De modo geral, houve predominância de domicílios rurais com abastecimento de água da rede geral (Figuras 11 e 12). No Centro Sul e Sertão Ocidental houve maior distribuição percentual de domicílios com abastecimento de água de cisterna. Em todos os recortes foram registrados percentuais significativos de domicílios com outras formas de abastecimento de água (carro-pipa, água da chuva armazenada de outra forma, rio etc.).

Quanto ao tipo de esgotamento sanitário (Figuras 13 e 14), em todos os recortes os percentuais foram mais elevados de domicílios com esgotamento via fossa rudimentar. Através dos casos discrepantes ou extremos, foram identificados setores rurais com elevados percentuais de domicílios com esgotamento sanitário via fossa séptica e rede geral. 
Figura 11. Avaliação de indicadores de abastecimento de água nos domicílios rurais dos Territórios do Planejamento do estado de Sergipe

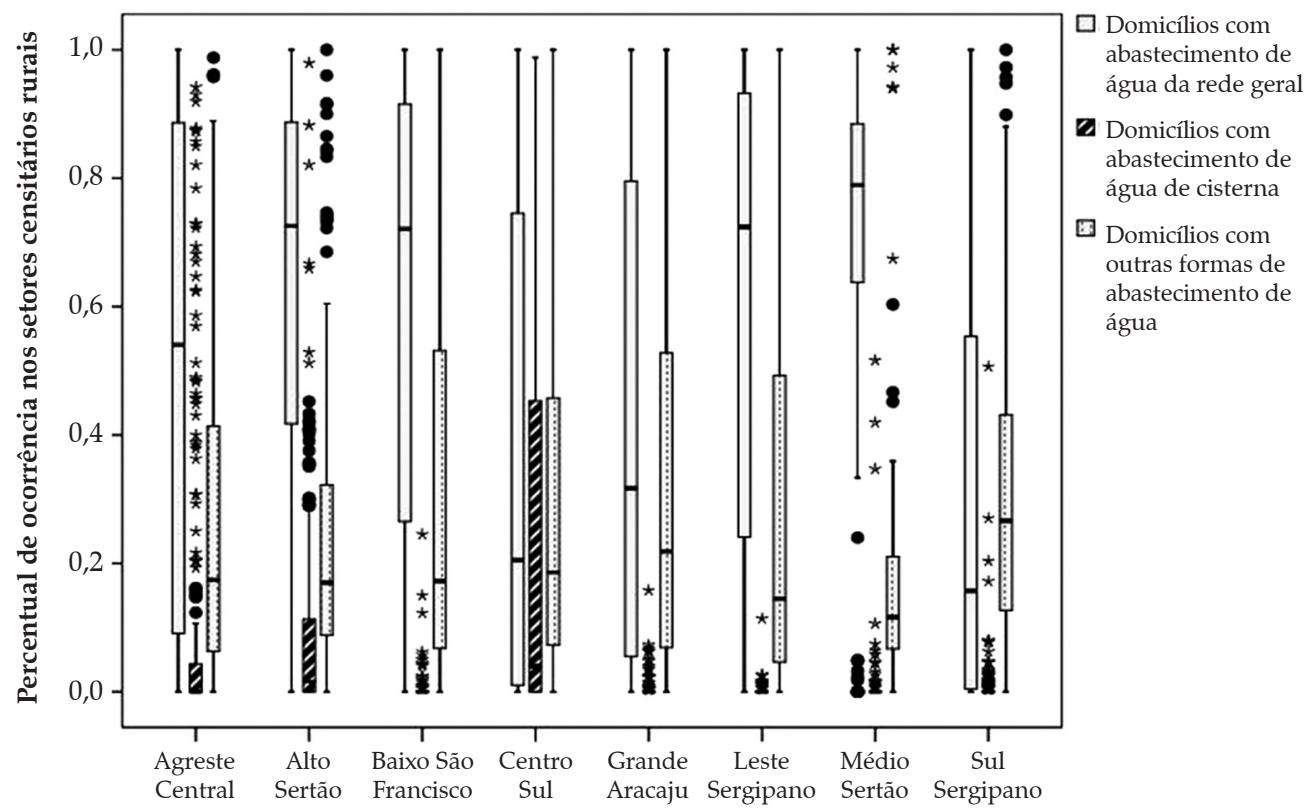

Territórios de Planejamento do estado de Sergipe

Fonte: Elaborada pelos autores.

Figura 12. Avaliação de indicadores de abastecimento de água nos domicílios rurais dos Territórios da Cidadania do estado de Sergipe

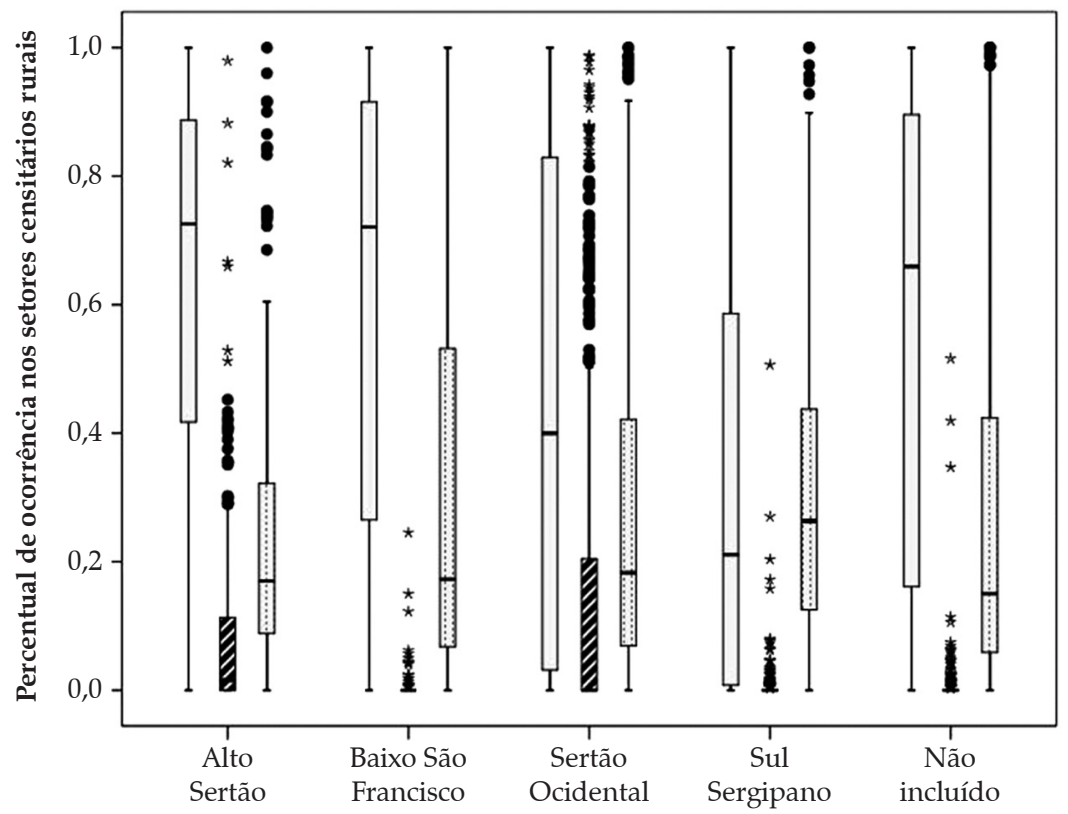

$\square$ Domicílios com abastecimento de água da rede geral

$\boldsymbol{Z}$ Domicílios com abastecimento de água de cisterna

Domicílios com outras formas de abastecimento de água

Territórios da Cidadania do estado de Sergipe 
Figura 13. Avaliação de indicadores de esgotamento sanitário nos domicílios dos Territórios de Planejamento do estado de Sergipe

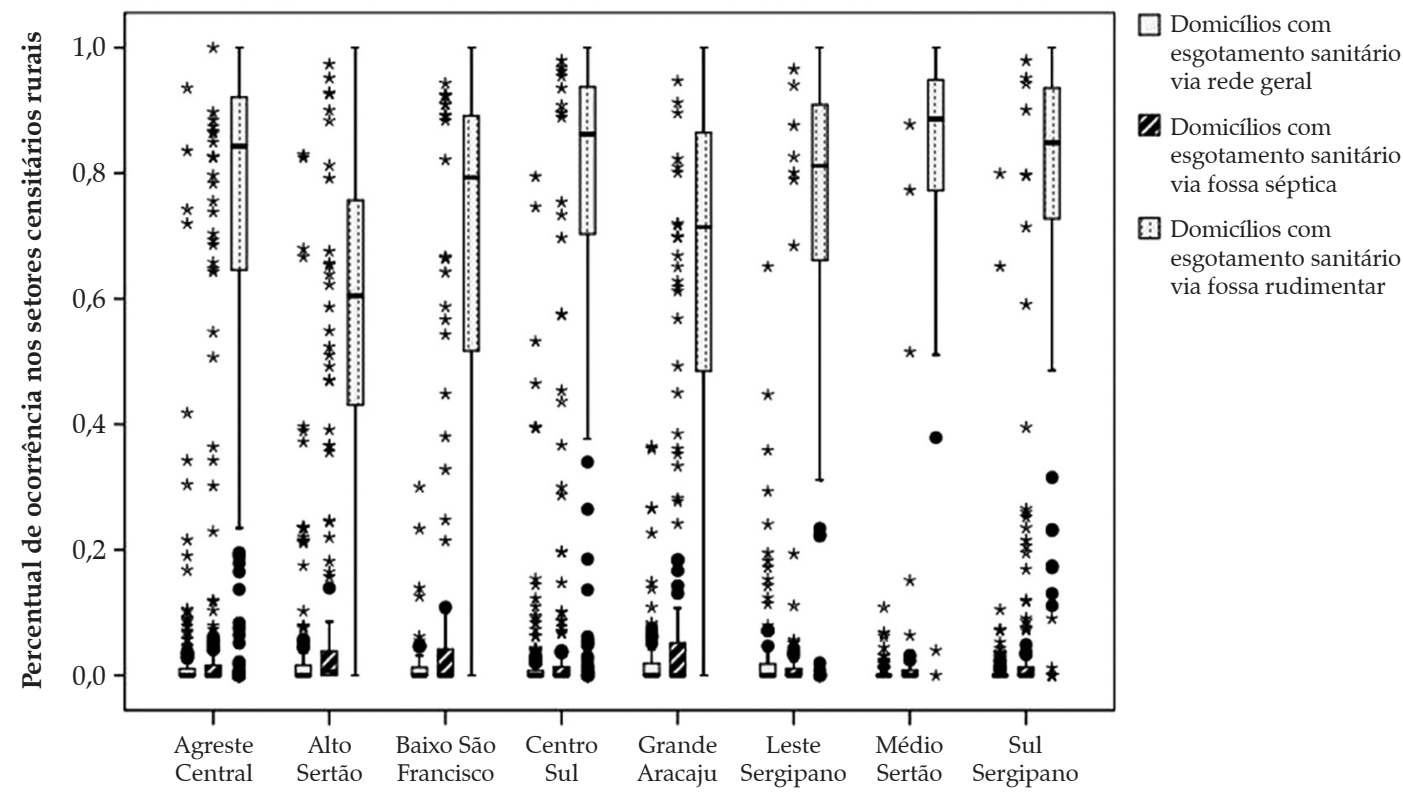

Territórios do Planejamento do estado de Sergipe

Fonte: Elaborada pelos autores.

Figura 14. Avaliação de indicadores de esgotamento sanitário nos domicílios dos Territórios da Cidadania do estado de Sergipe

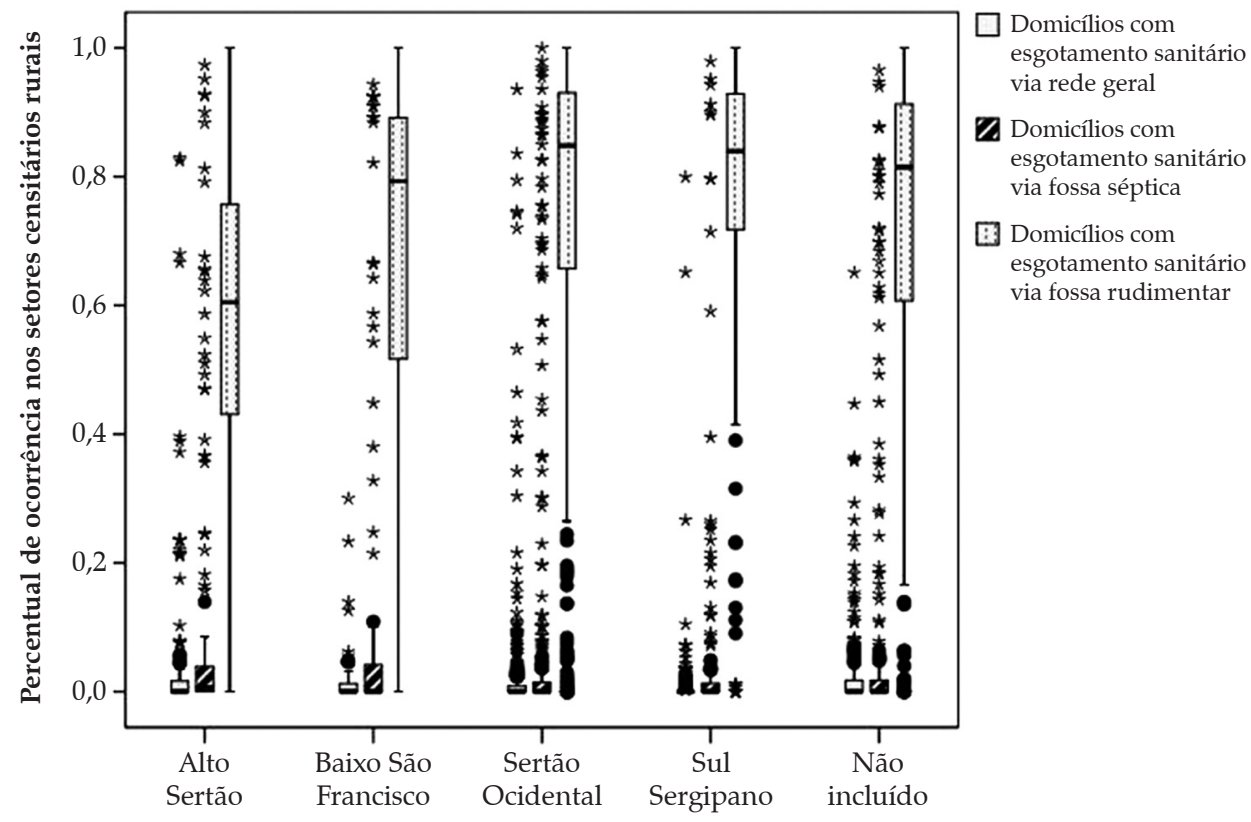

Territórios da Cidadania do estado de Sergipe

Fonte: Elaborada pelos autores. 


\section{Conclusões}

Nos recortes sergipanos (municípios, Territórios de Planejamento do Estado e Territórios da Cidadania) foram identificados agrupamentos de setores rurais caracterizados por apresentarem uma estrutura correlacional significativa. Em um dos agregados, os setores rurais apresentaram elevados percentuais de domicílios próprios e quitados; com energia elétrica e com serviço de coleta de lixo. No outro, os setores rurais apresentaram domicílios com condições habitacionais mais precárias, principalmente com relação à ausência de banheiros (incluindo sanitários) e prática da queima do lixo nas propriedades. Finalmente, um terceiro grupo, em que os setores rurais apresentaram domicílios com condições intermediárias das características habitacionais avaliadas.

O maior número de setores censitários rurais foi associado ao agrupamento que apresentou domicílios com condições menos favoráveis de moradia e maior número de habitantes. No Médio Sertão Sergipano foi possível observar menor percentual de domicílios sem banheiro e sem sanitário, e na Grande Aracaju, as características associadas à energia elétrica e à condição de ocupação do domicílio foram mais preocupantes (presença significativa de setores com baixos percentuais).

As análises realizadas por setores censitários ampliaram o universo de estudo de áreas rurais sergipanas, possibilitando identificar municípios que poderiam ser incluídos nos Territórios da Cidadania, caso as características avaliadas nesse estudo fossem suficientes para determinar a inclusão de um recorte/área no programa do governo federal.

De modo geral, os indicadores referentes aos domicílios próprios e energia elétrica foram bem avaliados em todos os recortes estudados. As grandes variações dos dados revelaram a existência de setores rurais em que uma parte considerável dos domicílios ainda é desprovida de indicadores básicos como, por exemplo, banheiro de exclusividade dos moradores. Os domicílios rurais sergipanos, em sua maioria, são abastecidos com água da rede geral e possuem banheiro com esgotamento sanitário via fossa rudimentar.
Os casos discrepantes e valores extremos possibilitaram identificar áreas rurais sergipanas que apresentaram as maiores desigualdades com relação às características avaliadas. Os cenários identificados poderão auxiliar no desenvolvimento de estudos práticos visando obtenção de informações mais precisas e úteis para a definição de políticas públicas.

\section{Referências}

BOUERI, R. e COSTA, M. A. (Eds.). Brasil em desenvolvimento 2013: estado, planejamento e políticas públicas. Brasília: Ipea, 2013.

BRASIL. Ministério do Desenvolvimento Agrário MDA. Secretaria de Desenvolvimento Territorial - SDT. Referências para a gestão social de territórios rurais. Brasília, DF: MDA. Série Documentos no 3, 2005.

Ministério do Desenvolvimento Agrário MDA. Secretaria de Desenvolvimento Territorial SDT. Territórios da cidadania: proposta do Ministério do Desenvolvimento Agrário para redução da desigualdade social no meio rural brasileiro. Brasília: BRASIL/MDA/SDT, 2007.

Ministério das Cidades. Plano Nacional de Habitação (PlanHab). Estudos Técnicos: Caracterização dos Tipos de Municípios. Brasília: Ministério das Cidades, Secretaria Nacional de Habitação, Departamento de Desenvolvimento Institucional e Cooperação Técnica, maio, 2009 (Consórcio Via Pública - LabHab-Fupam - Logos Engenharia).

Balanço de gestão: resultados das ações do programa desenvolvimento sustentável de territórios rurais (PRONAT) 2003-2010. Brasília,BRASIL/MDA/ SDT, 2010. 115 p.

CARVALHO, M. S., CRUZ, O. G. e NOBRE, F. F. Perfil de risco: método multivariado de classificação sócio-econômica de microáreas urbanas - os setores censitários da região metropolitana do Rio de Janeiro. Cadernos de Saúde Pública, Rio de Janeiro, v. 13, n. 4, p. 635-645, out./dez. 1997.

FIRETTI, R. et al. Desenvolvimento regional do Pontal do Paranapanema: percepção de futuro para a geração de empregos e renda. In: Sociedade Brasileira de Economia, Administração e Sociologia Rural, 48., 2010, Campo Grande. Anais... Campo Grande: SOBER, 2010. p. 1-20. 
GUMARÃES, M. D. A. Desenvolvimento de territórios rurais no Brasil: uma estratégia inovadora para o desenvolvimento rural sustentável. In: NASCIMENTO, P. P. et al. Inovações em desenvolvimento territorial: novos desafios para a Embrapa. Brasília, DF: Embrapa Informação Tecnológica, 2011. 424p.

HAIR JR., J. F. et al. Análise multivariada de dados. 6. ed. Porto Alegre: Bookman, 2009.

HASS, J. M. e NEUMANN, P. S. As transformações produtivas de uma região essencialmente agrícola e suas implicações. In: Encontro da Rede de Estudos Rurais, 4, 2010, Curitiba. Anais... Curitiba, 2010.

INSTITUTO BRASILEIRO DE GEOGRAFIA E ESTATÍSTICA - IBGE. Censo Demográfico 2010 Resultados do universo por setor censitário, 2011. Disponível em: < http://www.ibge.gov.br > Acesso em: maio 2012.

LOPES, E. S. A. e COSTA, J. E. Contradições, avanços e desafios na formação dos territórios rurais do Alto Sertão Sergipano e Agreste de Alagoas. In: LOPES, E. S. A. e COSTA, J. E. da (Orgs.). Territórios rurais e agricultura familiar no nordeste. São Cristóvão, SE: Editora UFS, 2009. 276p.

MIRANDA, L. e COSTA, F. Rede de avaliação para implementanção dos planos diretores participativos: relatório estadual de avaliação dos planos diretores participativos de Sergipe. Recife: Ministério das Cidades, 2009.

MIRANDA, C. e TIBURCIO, B. (Orgs.) Políticas públicas, atores sociais e desenvolvimento territorial no Brasil. Brasília, DF: IICA, 2011. (Série Desenvolvimento Rural Sustentável; v. 14). Disponível em: < http://repiica.iica.int/ DOCS/B2888P/B2888P.PDF > . Acesso em: 3 maio 2012.

MOREIRA, E. R. e TARGINO, I. Análise das Mudanças da Agricultura e dos Territórios Rurais: o litoral Paraibano. In: SABOURIN, E. e TEIXEIRA, O. A. Planejamento e desenvolvimento dos territórios rurais: conceitos, controvérsias e experiências. Brasília, DF: Embrapa Informação Tecnológica, 2002. 402 p.

PARANÁ. Instituto Paranaense de Desenvolvimento Econômico e Social. Programa Luz Fraterna: plano amostral e manual de instrução do pesquisador para a pesquisa do perfil socioeconômico dos beneficiários. Vol. 2. Curitiba: IPARDES, 2007.

SABOURIN, E. Métodos e instrumentos de planejamento e desenvolvimento territorial. In: SABOURIN, E. e TEIXEIRA, O. A. Planejamento $e$ desenvolvimento dos territórios rurais: conceitos, controvérsias e experiências. Brasília, DF: Embrapa Informação Tecnológica, 2002. 402 p. .e TEIXEIRA, O. A. Planejamento e desenvolvimento dos territórios rurais: conceitos, controvérsias e experiências. Brasília, DF: Embrapa Informação Tecnológica, 2002. 402 p.

SAQUET, M. A. Abordagens de concepções de território. 2. ed. São Paulo: Expressão Popular, 2010.

SCHNEIDER, S. e WAQUIL, P. D. Caracterização socioeconômica dos municípios gaúchos e desigualdades regionais. Revista de Economia e Sociologia Rural, Brasília, v. 39, p. 117-142, 2001.

. A abordagem territorial do desenvolvimento rural e suas articulações externas.Sociologias, Porto Alegre, ano 6, n. 11, p. 88-125, jan./jun. 2004.

SERGIPE. Secretaria de Estado do Planejamento, Orçamento e Gestão - SEPLAG. Governo de Sergipe. Sergipe: incluir para desenvolver: plano plurianual (PPA) 2012-2015. Aracaju, 2011. 293 p. Disponível em: <http://www.seplag.se.gov.br/attachments/ article/1124/PLANO \% 20PLURIANUAL \% $20 \% 20$ PPA\%20-\%202012-2015.pdf>. Acesso em: 2 maio 2012.

SILVA, M. A. S., SIQUEIRA, E. R. e TEIXEIRA, O. A. Abordagem conexionista para análise espacial exploratória de dados socioeconômicos de territórios rurais. Revista deEconomia e Sociologia Rural, Brasília, v. 48, n. 2, p. 429-446, abr.jun. 2010.

. et al. Modelagem social computacional como instrumento de análise de sistemas sociais territoriais complexos: o caso do Território Sul Sergipano, Brasil. Campo-Território, v. 9, n. 17, p. 55-85, 2014.

. O território como um sistema social complexo. In: FURTADO, B. A. et al. (Orgs.). Modelagem de sistemas complexos para políticas públicas. Vol. 1. Brasília: Instituto de Pesquisa Econômica Aplicada, 2015, p. 403-436.

SILVA, S. P. A abordagem territorial no planejamento de políticas públicas e os desafios para uma nova relação entre estado e sociedade no Brasil. Cadernos Gestão Pública e Cidadania, São Paulo, v. 17, n. 60, jan./ jun. 2012.

TEIXEIRA, O. A., MELO, R. L. e FRANÇA, V. L. A. A experiência de territorialização para o planejamento regional em Sergipe. Economia Política do Desenvolvimento, Maceió, v. 14, n. 12, set./dez. 2011, p. 91-128.

WANDERLEY, M. d. N. B. Que territórios, que agricultores, que ruralidades? In: CAVALCANTI, J. S. B., WANDERLEY, M. d. N. B. e NIEDERLE, P. A. Participação, Território e Cidadania: um olhar sobre a política de desenvolvimento territorial no Brasil. Vol. 1. Recife - PE: Universidade Federal de Pernambuco, 2014. $437 p$. 
